\title{
Forgeability and Machinability of Stir Cast Aluminum Alloy Metal Matrix Composites
}

\author{
Rabindra Behera ${ }^{1}$, S. Das ${ }^{1}$, D. Chatterjee ${ }^{2}$, G. Sutradhar S $^{*}$ \\ ${ }^{1}$ Department of mechanical Engineering, Jadavpur University, West Bengal, India \\ ${ }^{2}$ Department of mechanical Engineering, Bengal Engineering College, West Bengal, India \\ ${ }^{3}$ Department of mechanical Engineering, Jadavpur University, Kolkata, West Bengal, India \\ *Corresponding Author: cast_1963@ rediffmail.com, rabi_lisha@yahoo.com
}

\begin{abstract}
In the present paper, the aluminum alloy i.e. LM6 based composites reinforced with different weight fraction of SiC particles was produced by stir cast technique and the effect of reinforced ratios on the forgeability and the machinability was examined. The test results show that the increment in weight fraction of reinforcement particles in the matrix metal produced better mechanical property like hardness but the forgeability of the cast MMCs decreases. The forgeability of the as cast MMCs were also varied with the change in thickness of the casting. The results show that the forgeability of cast metal matrix composites at the mid section of the casting is minimum compared to both end section of a three-step casting. The effect of machining parameters, e.g. cutting speed and depth of cut on the surface roughness and cutting forces at constant feed rate was investigated during experimentation. The results show that higher weight percentage of SiCp reinforcement produced a higher surface roughness and needs higher cutting forces during machining operation. It has also observed that the depth of cut and the cutting speed at constant feed rate affected the surface roughness and the cutting forces. This practical research analysis and test results on the forgeability and machinability of Al/SiC-MMC will provide useful guidelines to the present day manufacturing engineers.
\end{abstract}

Keywords: MMC, Mechanical properties, Forgeability, Machining, Surface roughness

\section{INTRODUCTION}

Composite materials are engineered combinations of two or more materials in which tailored properties are achieved by systematic combinations of different constituents. Various types of 
engineered composites are prevalent in industry, including polymer matrix, ceramic matrix and metal matrix composites. Metal matrix composites (MMCs) are made of a continuous metallic matrix and one or more discontinuous reinforcing phases. The reinforcing phase may be in the form of fibers, whiskers or particles. Now a day's metal matrix composites (MMCs) are replacing conventional materials in many applications because of their superior properties such as high strength to weight ratio, hardness, stiffness and wear and corrosion resistances over conventional materials. Silicon carbide particle $(\mathrm{SiCp})$ reinforced aluminium-based MMCs are among the most common MMC and commercially available ones due to their economical production. In addition, the development of stir casting route for synthesis has brought down their cost to an acceptable level compared to those processed by powder metallurgy and spray casting process [1-3].

Particulate metal matrix composites have produced economically by conventional casting techniques. However, the stiffness, hardness and strength to weight ratio of cast MMCs are increased, but a substantial decrease in ductility has obtained. It has observed that some improvements in strength and ductility has found with the application of plastic forming processes i.e. forging to the cast composites. The forged MMCs having better mechanical properties compared to cast MMCs, such as it improves density, hardness and tensile strength etc. The forging process also avoids the use of secondary operation like machining. The forgeability is one of the important parameter, which gives information regarding the limitation of forging.

Ismail Ozdemir et.al [4] studied on the effect of forging on the properties of particulate-SiC reinforced aluminium-alloy composites. They have shown that the forged samples had strength values superior to those of the as-cast counterparts. After forging, the yield strength and tensile strength increased and there has improvement in ductility of the composite material. L. Ceschini et.al [5-6] studied on forging of the AA6061/23 vol. \% $\mathrm{Al}_{2} \mathrm{O}_{3} \mathrm{p} \& \mathrm{AA} 2618 / 20$ vol. $\% \mathrm{Al}_{2} \mathrm{O}_{3} \mathrm{p}$ composite: Effects on microstructure and tensile properties. They have shown that forging process induced a slight increase in hardness, tensile strength, elastic modulus and an evident increase in tensile elongation. SEM analyses of the fracture surfaces of the tensile specimens showed substantially similar morphologies for the as-cast and forged composites, both at room and high temperature. W. He, et.al [7] studied on the microstructure and mechanical properties of an $\mathrm{Al} / \mathrm{SiC}$ composite cold die forged gear. They have observed that cold forging of $\mathrm{SiC}$ reinforced Aluminium based metal matrix composites reduce the grain size, defects, and the fracturing of the secondary phase and SiC particulates. Because of a cold plastic deformation, a large crystal distortion occurred resulting in the increase in the dislocation density that enhanced mechanical properties. The minimum isostatic pressure to prevent fracturing during cold die forging has found to be $650 \mathrm{MPa}$.

Despite superior physical, mechanical properties and low production cost, particulate reinforced metal matrix composites are not widely used in industry because of their poor machinability. The 
presence of hard reinforcements, like particulates of silicon carbide ( $\mathrm{SiCp}$ ) and alumina $\left(\mathrm{Al}_{2} \mathrm{O}_{3} \mathrm{p}\right)$, makes machining, one of the shaping routes, very tedious. Although MMCs have often fabricated with near-net shape processing techniques, a number of secondary machining operations are always necessary in order to achieve the desired dimensional accuracy with good surface finish [8-10]. Machinability, an ill-defined term, encompassing such diverse properties as surface finish of the product, rate of tool wear, chip formation, and cutting forces required in machining, is the relative ease or difficulty of removing material in transforming a raw material into a finished component. Machinability testing aims at evaluation of the comparative machining performance of work piece, cutting tools, cutting fluids, and establishment of machining conditions producing a satisfactory part meeting desired dimensional surface finish and functional integrity economically.

Machinability of a particular material has evaluated by assessing any one of the following five parameters: (a) tool life or wear, (b) surface finish of test piece, (c) cutting force requirement, (d) power requirement, and (e) cutting temperature. Therefore, in the investigation of machinability, the cutting speed, feed rate and the depth of cut are important parameters.

El-Gallab and Reddy [11-14] have emphasized on the surface roughness in their study on the machinability of the $20 \%$ of SiCp reinforced Al-MMC. By performing dry turning tests with different cutting parameters, they have investigated the effect of processing parameters on surface roughness. They have found that large chip depths and high cutting speeds reduce the surface roughness. Li and Seah [15] investigated the machinability of MMC that contains different amounts of $\mathrm{SiC}$, especially in terms of the size and ratio of particle reinforcement. According to the results, when the percentage of reinforcement element in MMC exceeds a critical point, the wear in settings will increase.

Weinert [16] have analyzed the mechanical properties of and applied machining on the composites that include $\mathrm{SiC}$ and $\mathrm{Al}_{2} \mathrm{O}_{3}$ particles at different sizes and ratios and that has produced by pressure coating method. Sahin [17] studied the effect of different particle sizes of $\mathrm{SiC}$ and machinability properties of these Al-MMC materials. It was noticed that the hardness and density of Al-MMC increased by addition of SiCp. Ciftci et al. [18] examined tool wear in machining SiCp reinforced Al-MMC and reported that coated carbide cutting tool produced a longer tool life, but uncoated type provided a better surface quality. A. Manna et al. [19] studied on the machinability of $\mathrm{Al} / \mathrm{SiC}-\mathrm{MMC}$; they have shown that the built-up edges (BUE) have formed during machining of $\mathrm{Al} / \mathrm{SiC}-\mathrm{MMC}$ at high speed and low depth of cut. The tool wear i.e. flank wear rate is high at low cutting speed due to the generation of high cutting forces and formation of BUE.

J.T. Lin et.al [20] studied on machinability of a silicon carbide reinforced aluminium metal matrix composite (A 359/SiC/20 ) by using PCD (polycrystalline diamond) inserts. They have 
examined the machinability at cutting speeds of $300,500,700 \mathrm{~m} / \mathrm{min}$. and feed rates of $0.1,0.2 \&$ $0.4 \mathrm{~mm} / \mathrm{rev}$., while the depth of cut has kept constant. They have observed that the cutting time decreases with increasing cutting speeds and feed rates. They also concluded that the surface roughness increases with increasing feed rates at constant cutting speed and the best surface finish has achieved when the tool has slightly worn rather than when it is fully sharp. $\mathrm{N}$. Muthukrishnan et al. [21] investigated the machinability of Al-SiC metal matrix composites using PCD inserts. They have concluded that specific power consumption, which is one of the important indications of the machinability of the material decreases with the increasing cutting speed, feed and depth of cut in case of three different grades of PCD inserts (i.e. 1300, 1500, \& 1600). They have also observed that the surface finish was superior at higher cutting speeds and at lower feed rates.

In the present study hardness and forgeability of 5 and $10 \mathrm{wt} \%$ of SiCp reinforced LM6-MMC, the effect of SiCp reinforcement on the machinability and the effects of machining parameters such as cutting speed and depth of cut at constant feed rate on surface roughness and the cutting forces has been investigated.

\section{EXPERIMENTAL STUDIES}

\subsection{Production of Metal Matrix Composite}

Well-known aluminium alloy i.e. LM6, is used as matrix metal in the experiments for the fabrication of the composites that has been reinforced with 5 and $10 \mathrm{wt} \%$ of SiC particles of 400 mesh size. The chemical composition of the matrix material (LM6) was given in Table-1. The composites were fabricated by the liquid metal stir casting technique. The small ingots of LM6 is melted in clay graphite crucible using an electric resistance furnace and $3 \mathrm{wt} . \% \mathrm{Mg}$ has been added with the liquid metal, in order to achieve a strong bonding by decreasing the surface energy (wetting angle) between the matrix alloy and the reinforcement particles. The addition of pure magnesium has also enhanced the fluidity of the molten metal. Before mixing of the silicon carbide particles with the liquid LM6, particles was preheated at $900^{\circ} \mathrm{C}$ for 2-3 hours to make their surface oxidized. The melt was mechanically stirred by using a mild steel impeller and then the pre-heated silicon carbide particles (at $900{ }^{0} \mathrm{C}$ ) added with the stirred liquid metal. The processing of the composite was carried out at a temperature of $720^{\circ} \mathrm{C}$ with a stirring speed of 400-500 rpm. The melt was poured at a temperature of $690{ }^{0} \mathrm{C}$ into a stepped green silica sand mould. The 3D model of the pattern with its dimension is given in Fig.1. Fig. 2 shows the stirring of liquid LM6 with the preheated SiCp and Fig.3 shows the wooden pattern and casting of MMC. 
Table 1. Chemical Composition (LM6)

\begin{tabular}{|c|ccccccccccc|}
\hline Elements & $\mathbf{S i}$ & $\mathbf{C u}$ & $\mathbf{M g}$ & $\mathbf{F e}$ & $\mathbf{M n}$ & $\mathbf{N i}$ & $\mathbf{Z n}$ & $\mathbf{P b}$ & $\mathbf{S b}$ & $\mathbf{T i}$ & $\mathbf{A l}$ \\
\hline Percentage (\%) & $10-13.0$ & 0.1 & 0.1 & 0.6 & 0.5 & 0.1 & 0.1 & 0.1 & 0.05 & 0.2 & Remaining \\
\hline
\end{tabular}

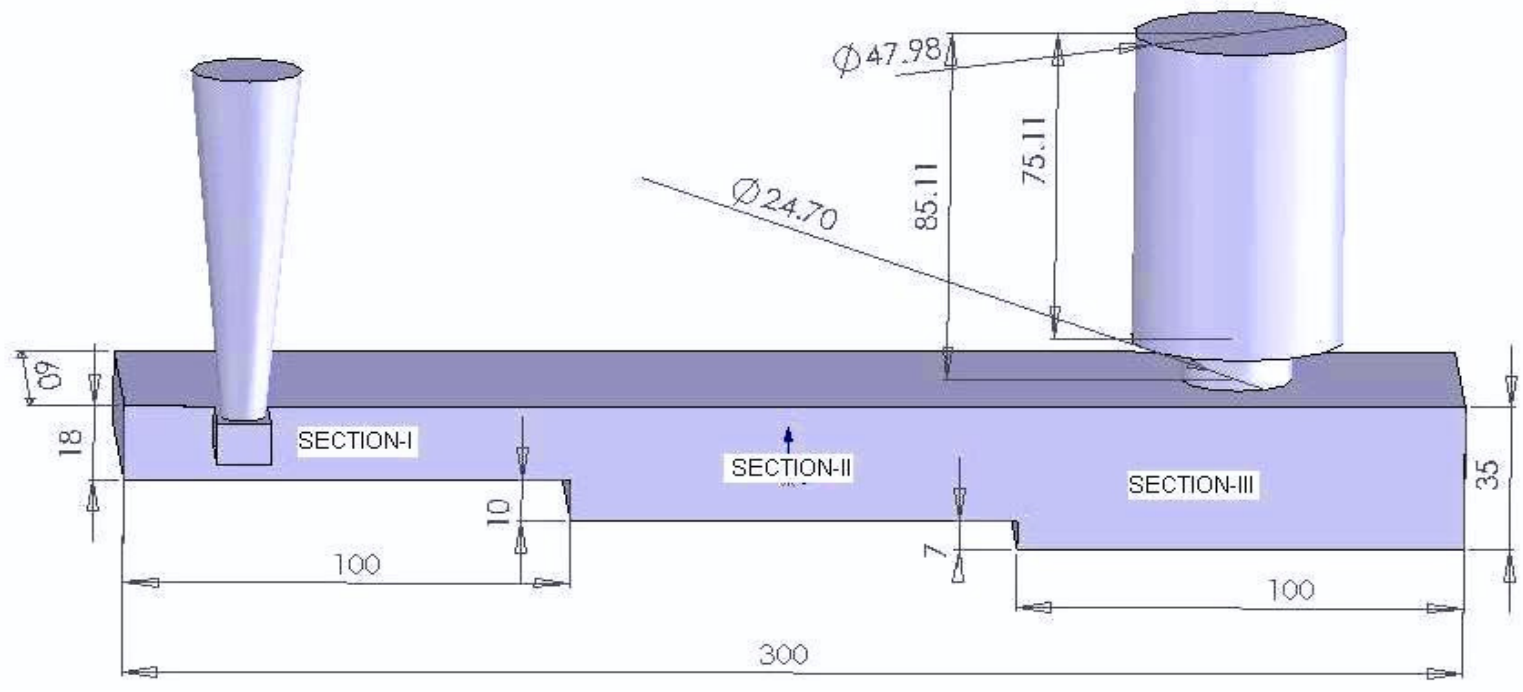

Fig.1.3D model of pattern with its dimensions in $\mathrm{mm}$.

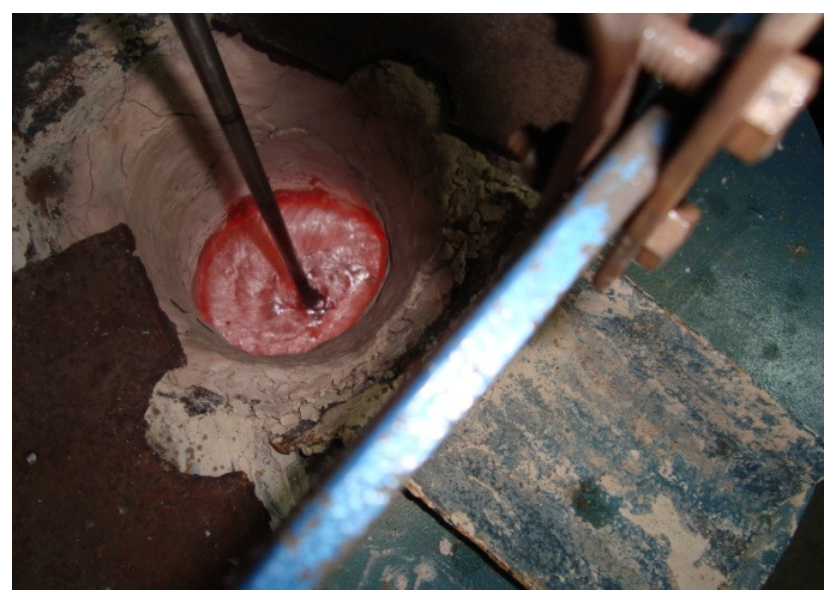

Fig.2. Stirring of liquid metal with preheated SiCp.

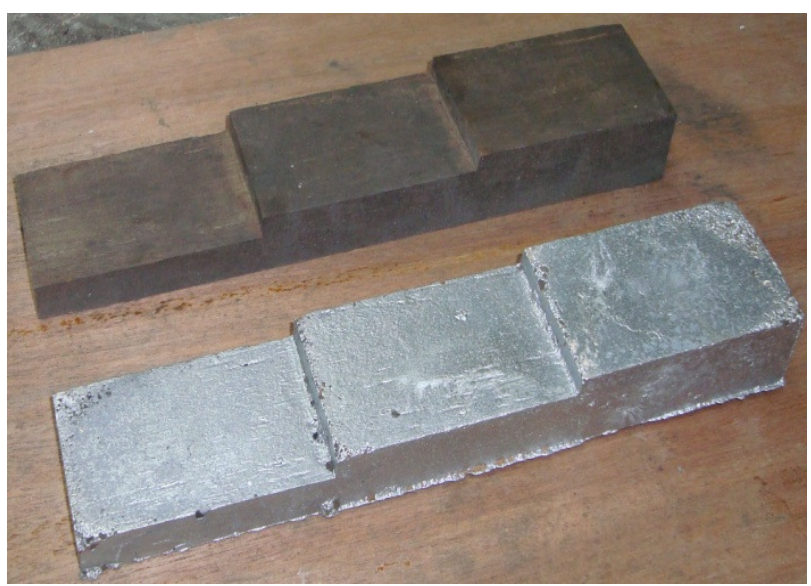

Fig.3. Wooden pattern and casting. 


\subsection{Performing Experiments}

The produced $\mathrm{SiC}_{\mathrm{p}}$ reinforced LM6 stepped cast MMCs was cut and the required sample prepared in order to examine the hardness and the forgeability. The samples were polished by 60 , 280 and 320 Grit papers and the hardness measured by using Wilson Rockwell Hardness Tester. The forgeability test has been carried in a conventional hydraulic press machine (PEECO Hydraulic Pvt. LTD., Manual Type, $200 \mathrm{KN}$ Capacity) at cold condition by upsetting method.

Machining tests of specimens have been carried out in a conventional universal lathe machine (Golden Machinery Corporation, 8speeds ranges from 30 to $750 \mathrm{rpm}$ ). The cutting tool has fitted in a rigid tool holder SYSCON made SPL 20083. The selected cutting tool was HSS and its geometry has given in Table-3. Chip breaker was not used during the experimental study. The machining tests were conducted under dry cutting process. The selected machining parameters are given in Table 2. The cutting forces (Ft, Ff and Fr) have been measured at different cutting speed and depth of cut at constant feed rate by using SYSCON Instrument made tool dynamometer. Surface roughness values ( $\mathrm{Ra}$ and $\mathrm{Rz}$ ) have been measured by using MITUTOYO make PORTABLE SURFACE ROUGHNESS TESTER.

Table 2. Experimental Conditions

\begin{tabular}{|lc|}
\hline Cutting tool & HSS \\
Cutting speed(m/min) & $27.64-61.82-118.62$ \\
Feed rate(mm/rev) & 0.05 (Constant) \\
Depth of cut(mm) & $0.5-1.0-1.5$ \\
Reinforcement ratio $\mathrm{SiC}_{\mathbf{p}}$ (wt. \%) & $5-10$ \\
\hline
\end{tabular}

Table 3. Cutting Tool Geometry

\begin{tabular}{|lccccc|}
\hline Tool Material & Back rake & SiChemical de rake & Clearance & Cutting edge \\
Nose radius & & \multicolumn{4}{c}{} \\
\& Grade & angle & angle & angle & angle & \\
HSS/M5 & $0^{0}$ & $10^{0}$ & $5^{0}$ & $15^{0}$ & $0.5 \mathrm{~mm}$ \\
\hline
\end{tabular}

\section{RESULTS AND DISCUSSION}

\subsection{Microstructure of As Cast MMCs}

Samples of as cast MMCs for metallographic examination were prepared by grinding through different size of grit papers followed by polishing with $6 \mu \mathrm{m}$ diamond paste. Then the samples were etched with the etchant i.e. Keller's reagent $(2.5 \mathrm{ml}$ Nitric acid, $1.5 \mathrm{ml} \mathrm{HCl}, 1.0 \mathrm{ml}$ 
HF,95.0 $\mathrm{ml}$ Water). The etched samples were dried by using electric drier and then the microstructure observed by using scanning electron microscope (SEM) (JEOL, JSM 6360). The microstructure of the as cast LM6 MMCs are shown in Fig.4 \&5 at different modulus of the casting. The micrograph of MMC castings at different section shows that the distributions of $\mathrm{SiC}$ particles are not uniform throughout the casting and segregation of particles are more in the eutectic region. This tendency may be attributed to the fact that the rate of cooling is not uniform throughout the casting due to change in thickness of the casting and slower rate of cooling in the sand mold.

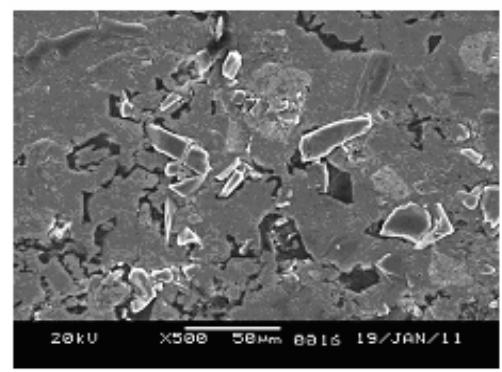

(a)

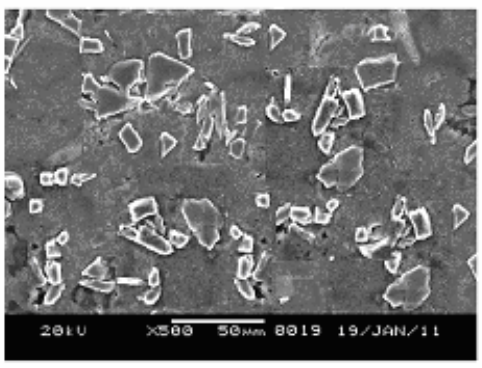

(b)

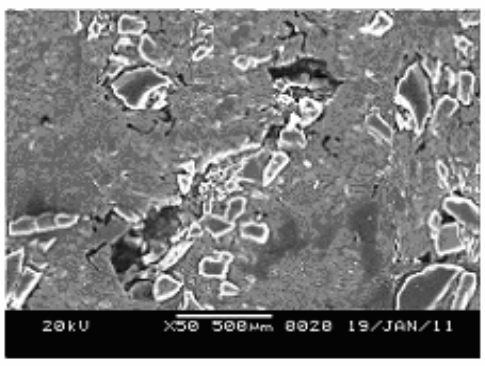

(c)

Fig.4. SEM micrograph of LM6\& 5Wt\% SiC Particle (a) section-I (b) section-II \& (c) section-III.

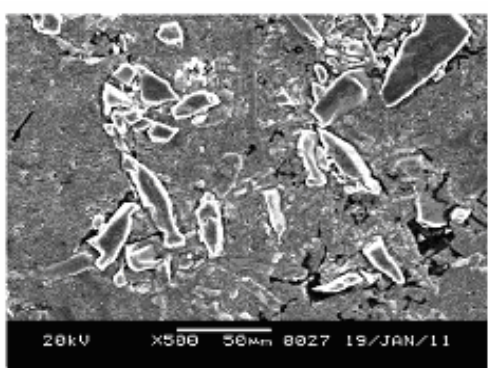

(a)

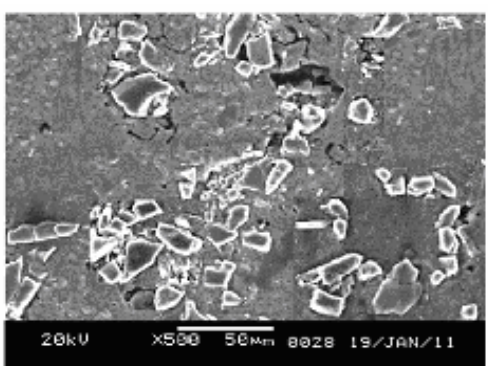

(b).

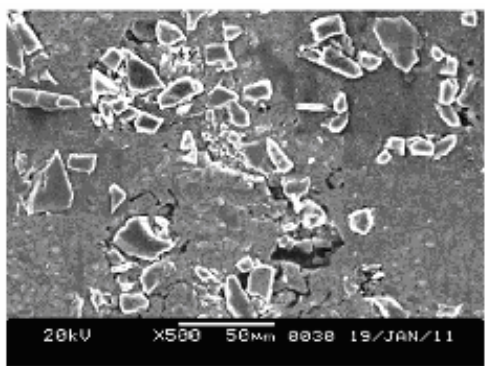

(c).

Fig.5. SEM micrograph of LM6\&10 Wt\% SiC particles

(a) section-I (b) section-II \& (c) section-III.

\subsection{Hardness and Forgeability}

The hardness of the casting should be uniform throughout the casting. This is, if the distribution of the reinforcement particles throughout the casting is uniform. However, other factors such as cooling rate, gravity effect and non-uniform distribution of the particles in the casting will give different values of hardness. The experimental data shows the hardness of the cast metal matrix composites increase proportionally by increasing the weight percentage of $\mathrm{SiC}$ particles in the 
casting and the value of hardness is higher in the middle section in comparison to the both end section of stir cast MMCs reinforced with $5 \mathrm{wt} \%$ \& $10 \mathrm{wt} \%$ of SiCp. Hardness value changed due to variation of reinforcement ratio and thickness of the casting, which has shown in Fig.6. This has occurred because of non-uniform cooling of the stepped casting during solidification of the cast metal. Moreover, the presence of extremely hard (2480 Knoop Hardness) SiCp in the matrix LM6 plays a significant role in increasing the hardness value. This experimental result was more or less similar by some researcher (the details given below), however they have manufactured the MMCs in different technique. Tamer Ozben et al. [22] determined on increasing the weight percentage of SiCp i.e. 5-15 in Al-Si alloy the hardness of squeeze cast metal matrix composites increases and maximum hardness found at $15 \mathrm{wt} \%$ of SiCp i.e. about $48 \%$ higher than the matrix metal. Y. Sahin et al. [17] reported that the hardness of the SiCp/AlSi alloy composites (produced by vacuum infiltration method) increased linearly with increasing particulate content in the matrix metal.

The limit of forgeability is expressed as the critical reduction in height, \% crit, by the following equation: $\%$ crit $=\frac{h_{\mathrm{r}}-\mathrm{h}_{\mathrm{i}}}{\mathrm{h}_{\mathrm{l}}} \times 100$,

where $\mathbf{h}_{\mathbf{i}}$ is the initial height of the sample in $\mathbf{m m}$. and $\mathbf{h}_{\mathbf{f}}$ is the final height of the sample in $\mathrm{mm}$. Critical reductions under unlubricated conditions only were compared to assess the forgeability of the experimental materials. The load was applied at room temperature on samples of different section of as cast MMCs reinforced with $5 \mathrm{wt} \%$ \& $10 \mathrm{wt} \% \mathrm{SiCp}$. At different load, the percentage of deformation investigated. These results have presented in Fig.7. The figure shown the percentage of deformation due to acting load is different at different section of the casting i.e. the percentage of deformation is lowest in section -II (middle section) comparison to Section-III $\&$ I. The percentage of deformation is highest in section-I and the percentage of deformation in section-III are remains in between section-I\&II. This indicates that the higher percentages of $\mathrm{SiC}$ particles have accumulated at the middle section of the casting i.e. at section-II, in comparison to the section-III \& I. The above result indicates that the distributions of silicon carbide particles are not uniform through out the casting. This has occurred because of non-uniform rate of solidification of liquid metal at different section of the casting. It has also observed that on increasing the weight percentage of silicon carbide particles in cast composites the percentage of deformation decreases that means the forgeability of cast composites decreases on increasing the reinforcement ratios, as the presence of very hard $\mathrm{SiCp}$ in the cast MMCs decreases its ductility and enhance its hardness \& brittleness.

K.S.See et al.[23] reported that forgeability of extruded $2618 \mathrm{MMC}_{15}(2618$ aluminium alloy $+15 \% \mathrm{SiCp}$ ) is approx.82\%, uniaxial upset forged $2618 \mathrm{MMC}_{15}$ is approx. $115 \%$,pseudo-isostatic forged $2618 \mathrm{MMC}_{15}$ is approx.114\% and triaxial upset forged $2014 \mathrm{MMC}_{15}$ is approx.143\% of its as-extruded counterpart. This report Ismail Ozdemir et al.[4] and L. Ceschini et al.[5-6] have reported that forging of MMCs enhance the mechanical properties (e.g. yield strength, tensile strength, hardness and also affect the micro structural properties. 


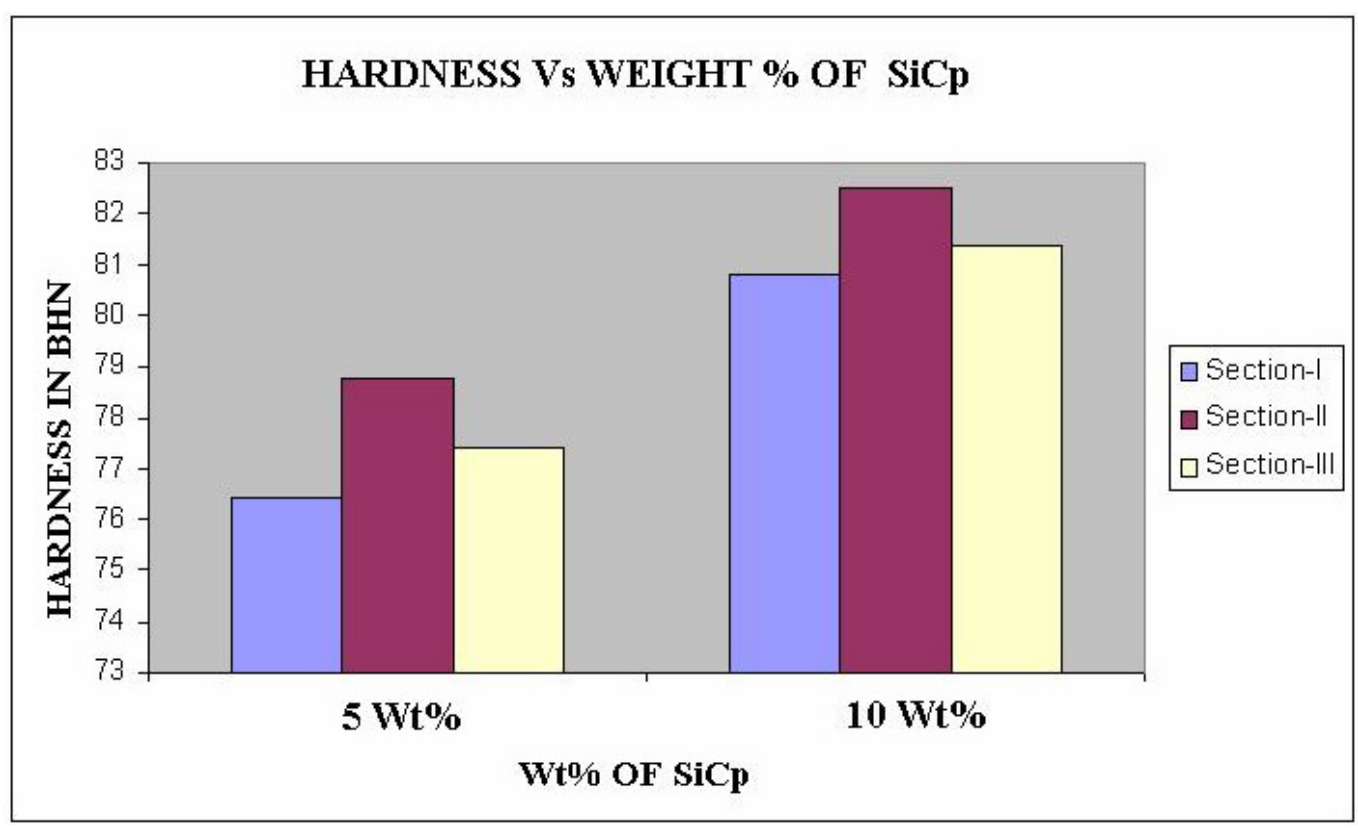

Fig.6. Hardness Vs Wt \% of SiCp

\section{LOAD Vs \% OF DEFORMATION (SECTION-I)}

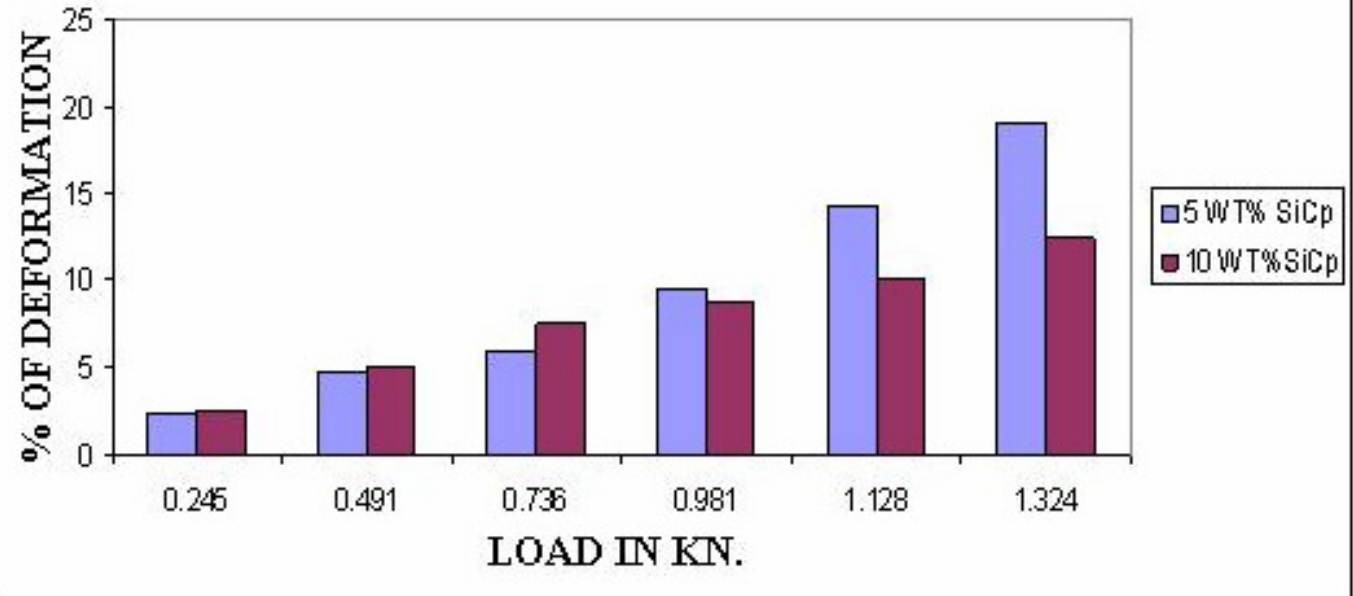

(a) 


\section{LOAD Vs \% OF DEFORMATION (SECTION- II)}

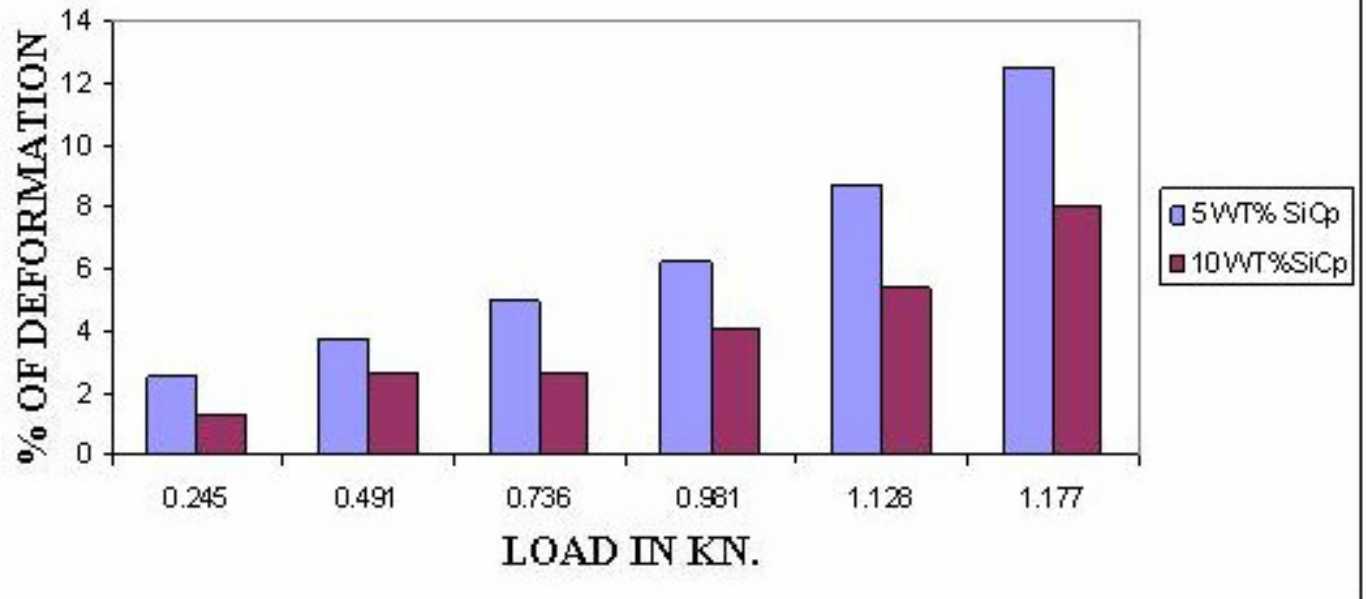

(b)

\section{LOAD Vs \% OF DEFORMATION (SECTION- III)}

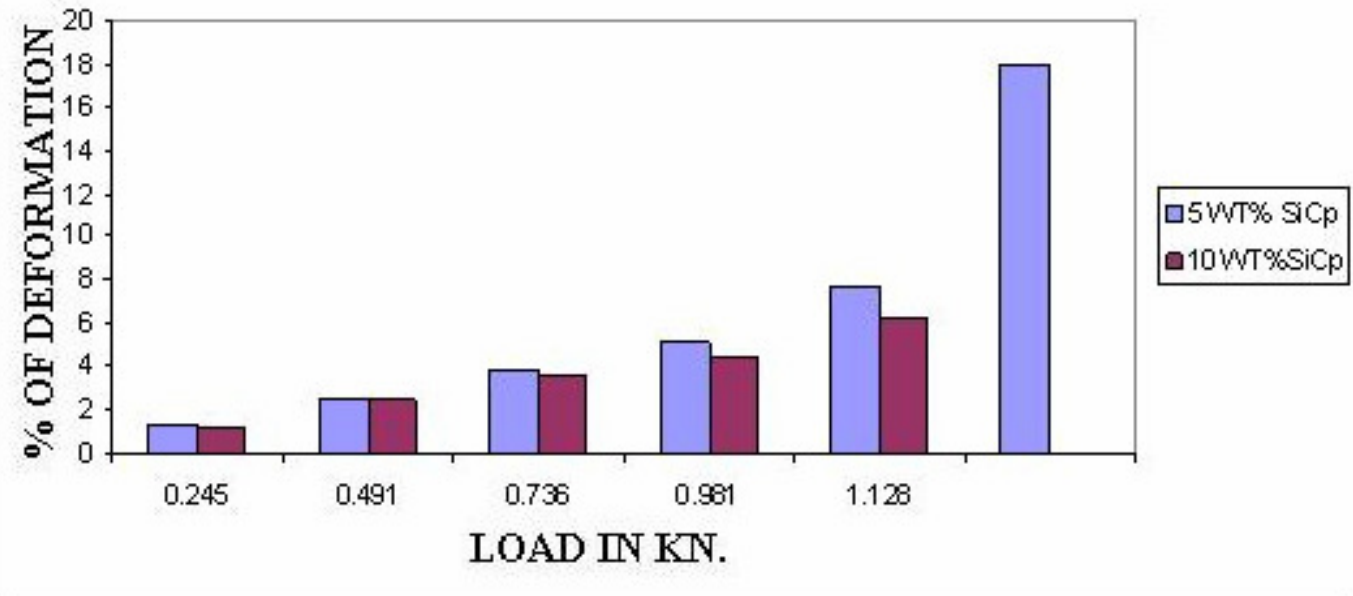

(c)

Fig.7. Load Vs \% of Deformation of as cast MMCs at different section of MMCs casting reinforced with $5 \mathrm{wt} \% \mathrm{SiCp}$ and $10 \mathrm{wt} \% \mathrm{SiC}$.

(a) section- I, (b) section- II \& (c) section- III. 


\subsection{Cutting Forces}

In the present investigation, dry turning operations have performed to evaluate the cutting forces such as 'Ft' (tangential component), feed force 'Ff' (thrust component) and 'Fr' the radial component for analyzing the machinability characteristics of LM6/SiC-MMC. The tangential component Ft, acts in the direction of cutting velocity vector is the main cutting force and is responsible for the cutting power needed. Fig.8 shows the effect of depth of cut on the cutting force (Ft), feed force (Ff) and radial force ( $\mathrm{Fr}$ ) at constant $0.05 \mathrm{~mm} / \mathrm{rev}$ feed and different cutting speed. The experimental results represent that for both the cast composites i.e. reinforced with 5 wt $\%$ \& $10 \mathrm{wt} \%$ of $\mathrm{SiCp}$, the cutting force components $\mathrm{Ft}, \mathrm{Ff}$ and $\mathrm{Fr}$ were increases on increasing the depth of cut. The maximum values of cutting force $(\mathrm{Ft})$, radial force $(\mathrm{Fr})$ and feed force $(\mathrm{Ff})$ are $78.48 \mathrm{~N}, 29.43 \mathrm{~N} \& 9.81 \mathrm{~N}$ respectively at depth of cut $0.5 \mathrm{~mm}$ and $157.0 \mathrm{~N}, 49.05 \mathrm{~N} \& 29.43 \mathrm{~N}$ respectively at $1.5 \mathrm{~mm}$ depth of cut during dry machining of MMCs reinforced with $5 \mathrm{wt} \%$ of SiCp. During dry machining of MMCs reinforced with $10 \mathrm{wt} \%$ of SiCp the cutting forces $\mathrm{Ft}$, Fr and $\mathrm{Ff}$ are $88.29 \mathrm{~N}, 49.05 \mathrm{~N} \& 19.62 \mathrm{~N}$ respectively at depth of cut $0.5 \mathrm{~mm}$ and $196.2 \mathrm{~N}, 98.1 \mathrm{~N} \&$ $49.05 \mathrm{~N}$ respectively at $1.5 \mathrm{~mm}$ depth of cut. The results shows that on increasing the weight percentage of $\mathrm{SiCp}$ in cast MMCs the required cutting forces are increased during machining of cast MMCs.

Fig.9 shows the effect of cutting speed on the cutting force (Ft), feed force (Ff) and radial force (Fr) at constant feed rate i.e. $0.05 \mathrm{~mm} / \mathrm{rev}$. and different depth of cut i.e. $0.5 \mathrm{~mm}, 1.0 \mathrm{~mm} \& 1.5 \mathrm{~mm}$, during machining of LM6/SiC-MMC reinforced with $5 \& 10 \mathrm{wt} \%$ of SiCp respectively. The results shows that for both the composites i.e. reinforced with $5 \mathrm{wt} \%$ \& $10 \mathrm{wt} \%$ of $\mathrm{SiCp}$ the cutting force components $\mathrm{Ft}$ and $\mathrm{Fr}$ increases on increasing the cutting speed and decreases on further increasing the cutting speed after certain speed. The cutting force components $(\mathrm{Ft})$ and (Fr) is maximum at cutting speed of $61.82 \mathrm{~m} / \mathrm{min}$ and then decreases on further increasing the cutting speed at constant depth of cut and feed. But, the feed force $(\mathrm{Ff})$ which acts in the direction of the tool travel was decreases on increasing the cutting speed for both the cast MMCs. 


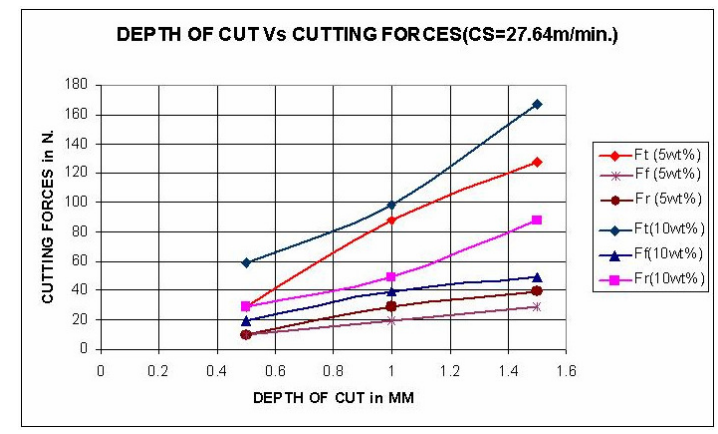

(a)

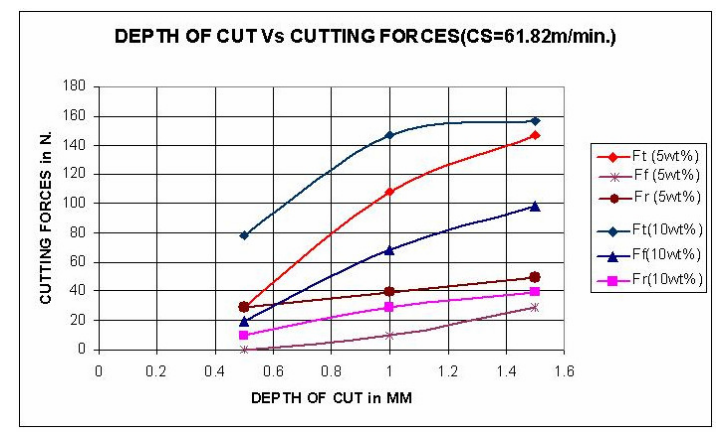

(b)

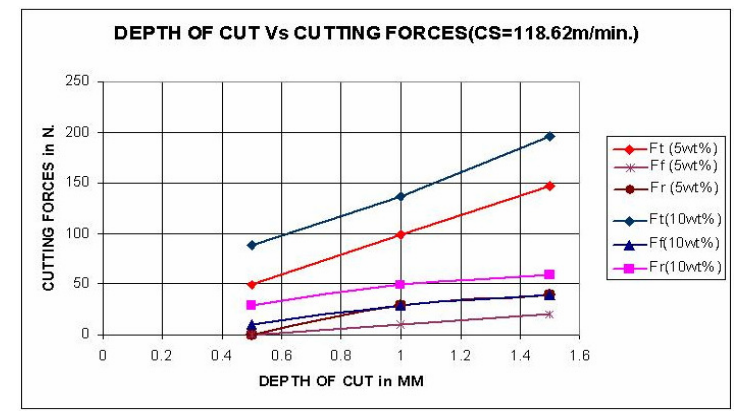

(c)

Fig. 8. Effect of depth of cut on Cutting Forces $(\mathrm{Ft}),(\mathrm{Ff})$ and $(\mathrm{Fr})$ at constant feed rate i.e. $0.05 \mathrm{~mm} / \mathrm{rev}$.

(a) Cutting speed $=27.64 \mathrm{~m} / \mathrm{min}$

(b) Cutting speed $=61.82 \mathrm{~m} / \mathrm{min}$

(c) Cutting speed $=118.62 \mathrm{~m} / \mathrm{min}$.

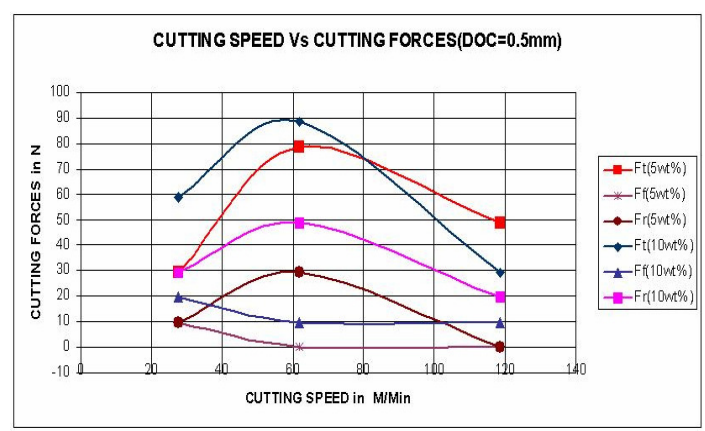

(a)

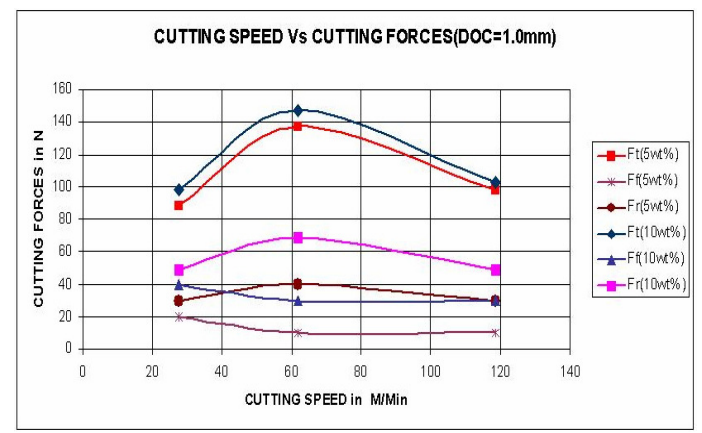

(b)

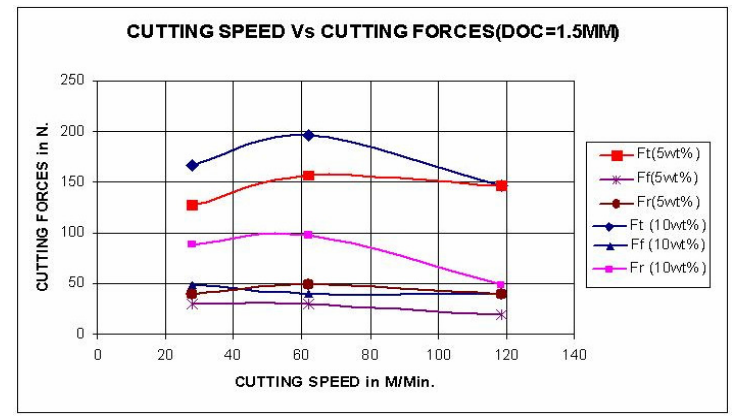

(c)

Fig. 9.Effect of Cutting speed on Cutting Forces $(\mathrm{Ft}),(\mathrm{Ff})$ and $(\mathrm{Fr})$ at constant feed rate i.e. $0.05 \mathrm{~mm} / \mathrm{rev}$.

(a) Depth of cut $=0.5 \mathrm{~mm}$

(b) Depth of cut $=1.0 \mathrm{~mm}$

(c) Depth of cut $=1.5 \mathrm{~mm}$. 


\subsection{Surface Roughness}

In this study, the effect of SiCp reinforcement to LM6-MMC material at different ratios on surface roughness have been investigated at selected cutting speed and depth of cut, keeping feed rate constant. The Fig.10 shows the relationship between surface roughness and cutting speed during dry turning at different depth of cut (i.e. $0.5 \mathrm{~mm}, 1.0 \mathrm{~mm} \& 1.5 \mathrm{~mm}$ ) and constant feed rate (i.e. $0.05 \mathrm{~mm} / \mathrm{rev}$.) of $5 \mathrm{wt} \%$ and $10 \mathrm{wt} \% \mathrm{SiCp}$ reinforced cast MMC material. It has observed that both the value of surface roughness i.e. Ra \& Rz decreases on increasing the cutting speed at different depth of cut and constant feed. The surface roughness is higher in case of samples having higher percentage of reinforcement compare to samples, which have relatively low percentage of reinforcement particles. This above results occurred might be due to the presence of extremely hard $\mathrm{SiCp}$ in the cast MMCs, during turning at low cutting speed the removed $\mathrm{SiC}$ particles has rolled over the machined surface and deteriorate the quality of the surface finish.

Tamer Ozben et al. [22] observed that when the cutting speed increases the surface roughness decreases and on further increasing the cutting speed, the surface roughness (Ra) increases during turning of Al-Si7Mg2-MMCs reinforced with 5 and $10 \mathrm{wt} \%$ of SiCp. But, for $15 \mathrm{wt} \% \mathrm{SiCp}$ reinforced MMCs the value of surface roughness increases with the cutting speed. A. Manna et al. [24] reported that dry turning of $\mathrm{Al} / \mathrm{SiC} / 15 \mathrm{p}$ at constant feed $(0.5 \mathrm{~mm} / \mathrm{rev}$.) and depth of cut $(0.5 \mathrm{~mm})$, the values of surface roughness $\mathrm{Ra} \& \mathrm{Rt}$ are low at high cutting speed and vice versa. They also reported that on increasing the feed rate and depth of cut, the surface roughness increases and when the value of feed rate tripled i.e. from 0.25 to $0.75 \mathrm{~mm} / \mathrm{rev}$. then the value of surface roughness $(\mathrm{Ra})$ increases by $40 \%$.

In Fig. 11, the surface roughness has examined in terms of increase in depth of cut. Because of examination, on increasing the depth of cut during turning at constant feed rate and different cutting speed, the surface roughness values i.e. Ra \& Rz increases. It has been also observed that the samples having higher percentage of reinforcement particles i.e. SiCp have high surface roughness compare to MMC samples having lower percentage of reinforcement particles. As during dry machining of this cast MMCs, the removal of $\mathrm{SiC}$ particles cause some small gaps on the machined surface. It has estimated that this condition caused an increase in the surface roughness of experiment samples that have higher weight percentage of SiCp compare to lower weight percentage of SiCp. Tamer Ozben et al. [22] reported that on increasing the percentage of $\mathrm{SiCp}$ in Al-Si7Mg2 alloy matrix, the surface roughness value $(\mathrm{Ra})$ increases with feed rate during turning of the MMCs. Jinfeng Leng et al. [25] reported that with the addition of 3-7\% flaky graphite particles, the machinability of $\mathrm{SiC} / \mathrm{Al}$ composites improved greatly and the tool life has prolonged by $10-130 \%$. 


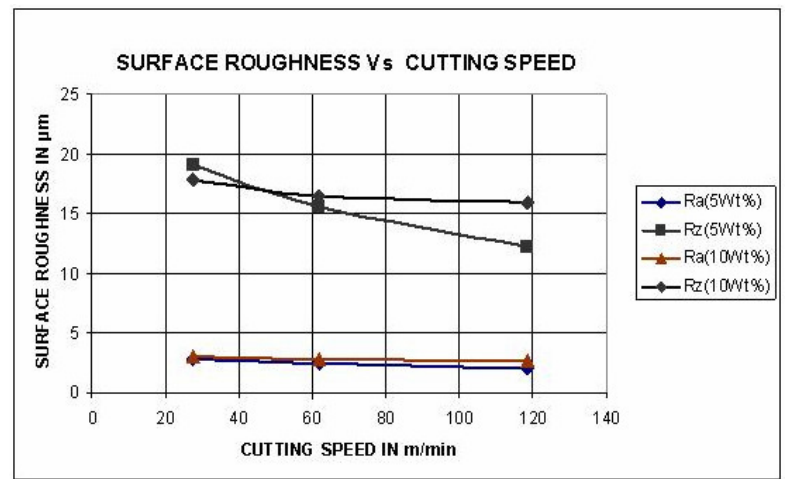

10(a)

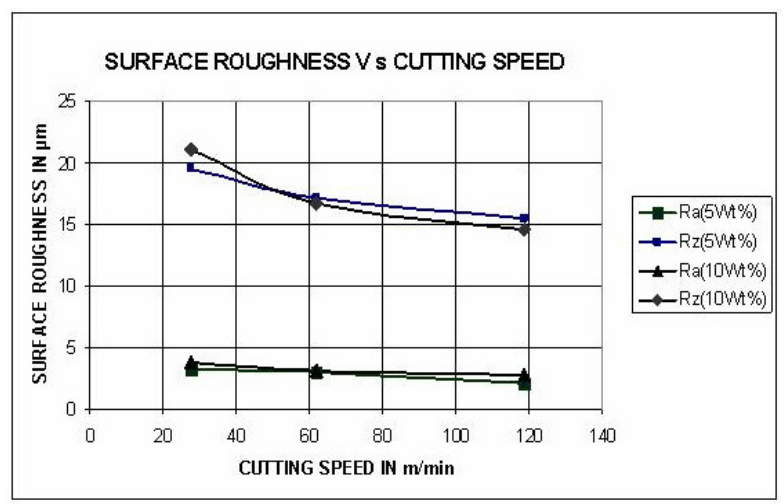

10(b)

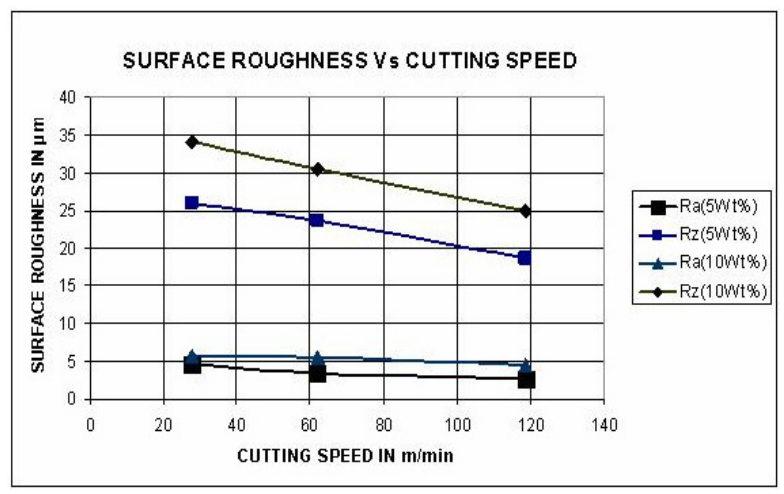

10 (c)

Fig.10. Effect of Cutting Speed on Surface

Roughness at constant feed rate

i.e. $0.05 \mathrm{~mm} / \mathrm{rev}$.

(a) Depth of Cut $=0.5 \mathrm{~mm}$.

(b) Depth of Cut $=1.0 \mathrm{~mm}$.

(c) Depth of Cut $=1.5 \mathrm{~mm}$.

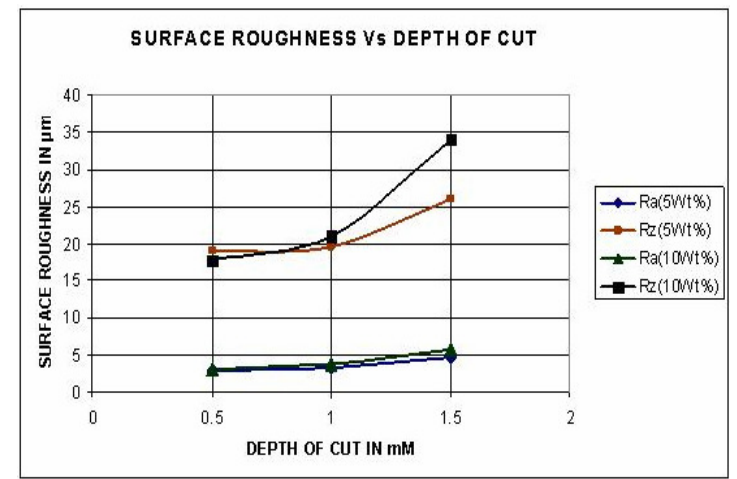

11(a)

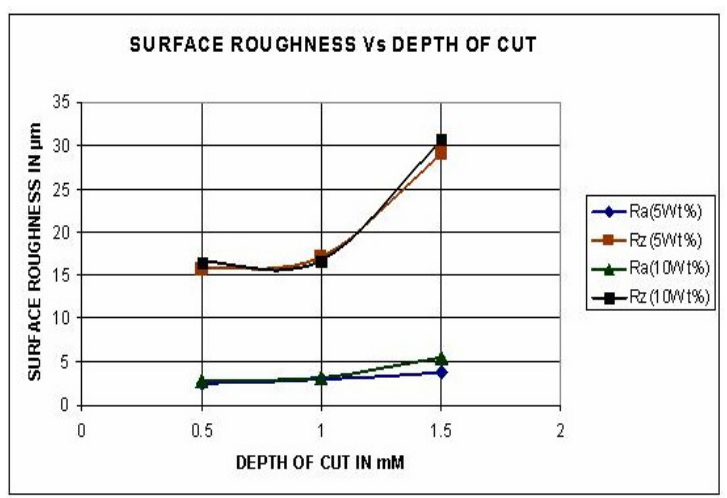

11(b)

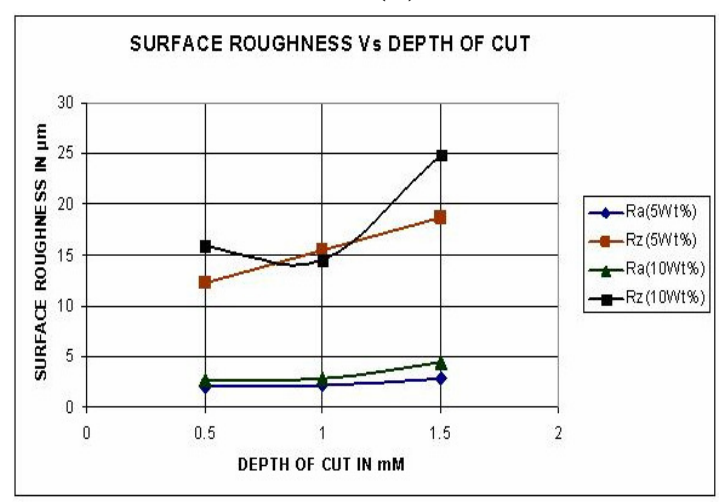

11(c)

Fig. 11. Effect of Depth of Cut on Surface Roughness at constant feed rate i.e. $0.05 \mathrm{~mm} / \mathrm{rev}$.

(a) Cutting speed $=27.64 \mathrm{~m} / \mathrm{min}$.

(b) Cutting speed $=61.82 \mathrm{~m} / \mathrm{min}$.

(c) Cutting speed $=118.62 \mathrm{~m} / \mathrm{min}$. 


\section{CONCLUSIONS}

In the present investigation, the hardness and forgeability of stir cast LM6 reinforced with 5 and $10 \mathrm{wt} \% \mathrm{SiCp}$ was examined at the different section of the stepped casting and the effect of weight percentage of SiCp on machinability of the cast MMCs has been evaluated. The effect of machining parameters like cutting speed and depth of cut on machinability has also studied at constant feed rate.

i. With increasing the weight percentage SiCp in cast MMCs, the hardness increased and the value of the hardness is high at the middle section of the casting compared to both end section of the casting. The forgeability i.e. percentage of deformation decreases on increasing the percentage of $\mathrm{SiCp}$ and the middle part of the casting (i.e. section-II) shows low forgeability comparison to the both end sections in the step casting component because accumulation of higher percentage of $\mathrm{SiCp}$. That indicates the distribution of SiCp is not uniform through out the casting.

ii. The machinability of MMC is different from the traditional materials because of presence abrasive reinforcement particles. During turning operation, the cutting forces $(\mathrm{Ft}, \mathrm{Ff} \&$ Fr) have increased with increase in weight percentage of SiCp.

iii. At constant feed rate and different cutting speed, the cutting forces are increases on increasing the depth of cut. That indicates the power consumption during machining of aluminium alloy MMCs will increases on increasing the depth of cut at the same condition.

iv. The surface roughness of as cast MMCs enhanced on increasing the weight percentage of SiCp. During turning of as cast LM6-MMC samples, the surface roughness increases on increasing the depth of cut at constant feed rate and different cutting speed.

v. Surface roughness also affected by cutting speed during turning of aluminium MMCs that is on increasing the cutting speed at constant feed rate the surface roughness decreases.

\section{ACKNOWLEDGEMENT}

Authors thankfully acknowledge the financial support provided by U.G.C, New Delhi under Major Research Project Grant [F.No.32-88/ 2006 (SR) dated 09.03.2007] without which this work could not be attempted.

\section{REFERENCES}

1. Pramanik, A., Zhang, L.C. and Arsecularatne, J.A., "Prediction of cutting forces in machining of metal matrix composites", International Journal of Machine Tools and Manufacture, 46 (2006), pp.1795-1803.

2. Rohatgi, P., “Advances in cast MMCs”, Adv. Mater. Process, 2(1990), pp. 38-44. 
3. Allison, JE and Cole, GS, "Metal matrix composite in the automotive industry: Opportunities and Challenges", JOM January: (1993), pp.19-24.

4. Ismail OÈ zdemir, UÈ mit CoÈ cen and Kazim OÈ nel, "The effect of forging on the properties of particulate-SiC- reinforced aluminium-alloy composites", Composites Science and Technology, 60(2000),pp. 411-419.

5. Ceschinia, L., Minakb, G., Morria, A. and Tarterini , F., "Forging of the AA6061/23 vol.\%Al2O3p composite: Effects on microstructure and tensile properties", Materials Science and Engineering A, 513-514,pp.176-184.

6. Ceschinia, L., Minakb, G. and Morri, A., "Forging of the AA2618/20 vol.\% A12O3p composite: Effects on microstructure and tensile properties", Composites Science and Technology ,69(2009) pp.1783-1789.

7. He, W., Zhang, Y.F., Lee, K.S., Lu, L., Xie, S.S. and Jin, Q.J., "Microstructure and mechanical properties of an $\mathrm{Al} / \mathrm{SiCp}$, composite cold die forged gear." Materials \& Design.17(2), (1996),pp. 97-102.

8. Cronjager, L. and Meister, D., "Machining of fibre and particle reinforced aluminium". Ann CIRP 41(1) (1992),pp.63-66.

9. Loony, LA., Monaghan, JM.,Reilly, P O. and Toplin, DRP., "The turning of an A1/SiC metal matrix Composite”. J Mater Process Technol, 33(4) (1992),pp. 453-468.

10. Weinert, K. and Konig, W. "A consideration of tool wear mechanism metal matrix composite (MMC)". Ann CIRP 42(1) (1993),pp.95-98.

11. Gallab, El. and Sklad, M.. "Machining of Al/SiC particulate metal-matrix composites. Part I. Workpiece surface integrity”, J.Mater. Process. Technol. 83(1998a), pp. 277-285.

12. Ejiofor, J.U. and Reddy, R.G., "Developments in the processing and properties of particulate Al-Si composites”, J. Mater. Soc.,79(1997), pp.31-34.

13. Gallab, El. and Sklad, M., "Machining of Al/SiC particulate metal-matrix composites. Part I. Tool performance”, J. Mater.Process. Technol., 83(1998b), pp.151-158.

14. Gallab, El. and Sklad, M., "Machining of Al/SiC particulate metal-matrix composites. Part III.Comprehensive tool wear models", J.Mater. Process. Technol., 10(2000),pp.10-20.

15. Li, X. and Seah, W.K.H., "Tool wear acceleration in relation to work piece reinforcement percentage in cutting of metal matrix composites". Wear, 2472(2001),161-171.

16. Weinert, K., "A consideration of tool wear mechanism when machining metal-matrix composites (MMC)", Ann. CIRP 42(1993), pp.95-98.

17. Sahin, Y., "Preparation and some properties of SiC particle reinforced aluminium alloy Composites", Mater. Des., 24-28(2003),671-679.

18. Ciftci, I., Turker, M. and Seker, U., "CBN cutting tool wear during machining of particulate reinforced MMCs”, Wear 257 (9/10) (2004), 1041-1046.

19. Manna, A. and Bhattacharyya, B., "A study on machinability of Al/SiC-MMC", Journal of Materials Processing Technology, 140(2003),711-716.

20. Lin, J.T., Bhattacharyya, D. and Lane, C., "Machinability of a silicon carbide reinforced aluminium metal matrix composite", Wear, 181-483(1995), 883-888. 
21. Muthukrishnan, N., Murugan, M and Prahlada, Rao K., "An investigation on the machinability of Al-SiC metal matrix composites using PCD inserts”, Int.J. Adv.Manuf. Technol. 38(2008),447-454.

22. Ozben, T., Kilickap E., and Cakır, O., "Investigation of mechanical and machinability properties of SiC particle reinforced Al-MMC", J. Mater. Process.Technol, 198, 220- 225 (2008).

23. See, K.S. and Dean, T.A., "The effects of pre-forge processing on forgeability and mechanical properties of co- sprayed aluminium-based MMCs", J. Mater. Process. Technol, 71(1997), 314- 321.

24. Manna, A. and Bhattacharyya, B. , "Influence of machining parameters on the machinability of particulate reinforced Al/SiC- MMC”, Int. J. Adv. Manuf.Technol.,25(2005)850-856.

25. Leng, J., Jiang, EL., Zhang, Q., Wu, G., Sun, D. and Zhou, Q., "Study of machinable SiC/Gr/Al composites", 43(2008)6495-6499. 